\title{
A Convenient Method for the Preparation of Alkanolamides
}

\author{
Ho Sik Rho, Heung Soo Baek, Duck Hee Kim, and Ih Seop Chang
}

\author{
$R \& D$ Center, AmorePacific Corporation, Yongin, Kyounggi 449-729, Korea. *E-mail: thiocarbon@freechal.com \\ Received Sepember 27, 2005
}

Key Words : Alkanolamide, Ethylchloroformate, Mixed anhydride

Long chain alkanolamides have attracted considerable interest because of their intrinsic amphiphilic properties. ${ }^{1}$ They are frequently used as a surfactant for cosmetics ${ }^{2}$ and pharmaceutical use. ${ }^{3}$ In the course of the synthesis of alkanolamides, control of chemoselective amide formation over competing $O$-acylation of neighboring hydroxyl groups plays a key step. Several methods have been developed which include a few enzymatic synthesis ${ }^{4}$ and the reaction of carboxylic acid with amino alcohols by the aid of $N$-ethoxy1-ethoxy-dihydroquinone (EEDQ) in ethanol reflux condition. ${ }^{5}$ However, these known methods have drawbacks for example narrow application scope in enzymatic reaction, longer reaction time and harsh reaction condition. Recently, we have reported that chemoselective $\mathrm{N}$-acylation of amino alcohols promoted by magnesium oxide in aqueous organic solution. ${ }^{6}$ Although the use of this method was successful in many cases, preparation of acid chloride is not always easy so there is still a strong need for more convenient amidation method of amino alcohols. Now we report a useful procedure for the efficient and chemoselective amidation of hydrophilic amino alcohols with mixed anhydride generated from carboxylic acid and ethylchloroformate (Scheme 1).

Treatment of benzoic acid 1 a with ethylchloroformate (1.1 equiv) in the presence of $N$-methylmorpholine (1.1 equiv) in THF gave mixed anhydride, which subsequently reacted with tris(hydroxymethyl)aminomethane 3a in DMF and TEA (1.1 equiv) to give alkanolamide $4 \mathbf{a}$ in $85 \%$ yield (entry 1 in Table 1). The formation of by-products such as $O$-acylated and $N, O$-diacylated derivatives have not been observed in HPLC analysis.

After the disappearance of mixed anhydride checked by TLC analysis, DMF was evaporated in vacuo. The residue of reaction mixture was extracted with ethyl acetate, washed with water. The organic layer was analyzed by HPLC. As shown in Figure 1, small amount of benzoic acid were detected without by-products. Benzoic acid was easily separated by flash chromatography. As an additive for the synthesis of mixed anhydride, TEA as well as $N$-methylmorpholine was effective. Of solvents tested, THF and ether were suitable. Using aliphatic carboxylic acid $\mathbf{2 b}$, alkanolamide $\mathbf{4 b}$ was also obtained in high yield (entry 2). Further, this method was successfully extended to other acids containing acid or base-sensitive groups such as cyclic disulfide, ester and acetate (entry 3, 4 and 5). In all cases, byproducts that are usually formed in the reaction of acid chlorides with amino alcohols were not detected. ${ }^{7}$ Preferential amine selectivity can be explained by assuming low electrophilicity of mixed anhydride comparing with acid chloride. Because of its low electrophilicity, more nucleophilic amino groups may only react with mixed anhydride. The reaction also worked well for the other hydrophilic amine such as ethanolamine, DL-serine methyl ester and diethanolamine. The desired alkanolamides $\mathbf{4 f}, \mathbf{4 g}$ and $\mathbf{4 h}$

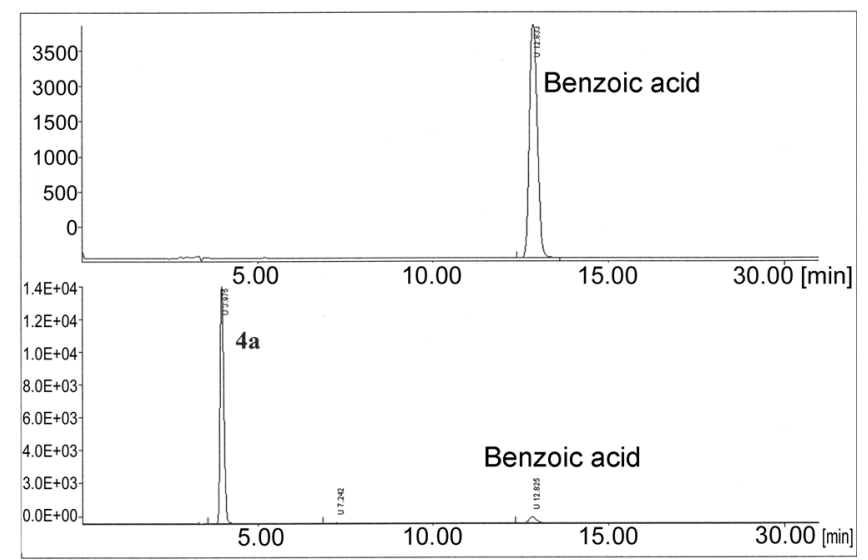

Figure 1. HPLC profile of the synthesis of compound $\mathbf{4 a}$.

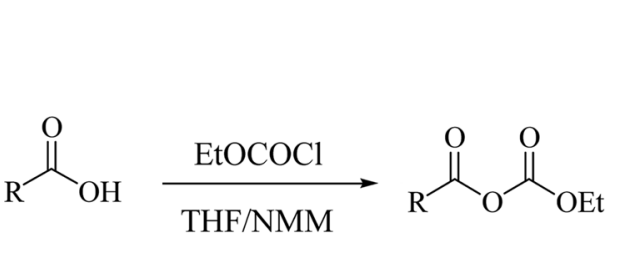

1

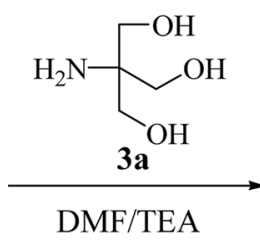<smiles>[R]C(=O)NC(CO)(CO)CO</smiles>

4

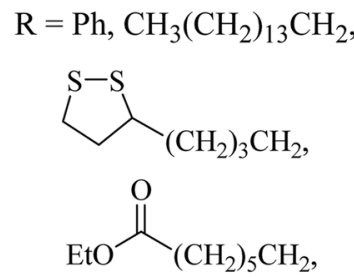

p-AcO-Ph, 
Table 1. Conditions for the synthesis of alkanolamides

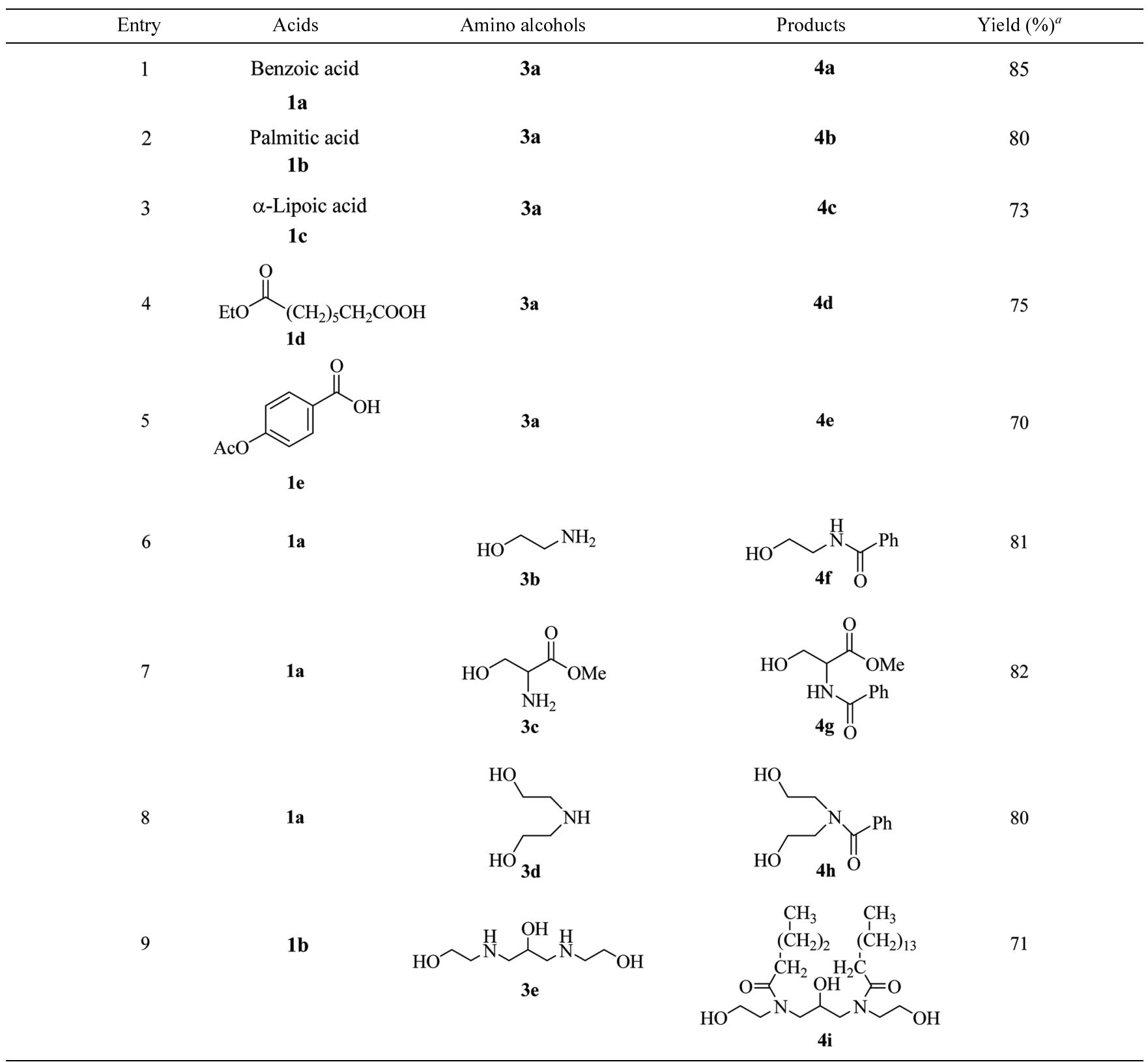

${ }^{a}$ Isolated yields.

were obtained in high yields (entry 6, 7 and 8). Finally, 1,3bis[(hydroxylmethyl)amino]propan-2-ol (BHAP, 3e) afforded the diamide (4i) in $71 \%$ yield.

In summary, we have developed an efficient and chemoselective $N$-acylation method of amino alcohols by the treatment with mixed anhydrides generated from various acids and ethylchloroformate. The use of mixed anhydride afforded amine selectivity due to its relatively low electrophilicity. This method was suitable for the synthesis of alkanolamides containing acid or base-sensitive groups.

\section{Experimental Section}

Typical Procedure : Preparation of 4a. To a solution of benzoic acid (900 mg, $7.3 \mathrm{mmol}$ ) and $N$-methylmorpholine (812 mg, $8.0 \mathrm{mmol})$ in THF $(10 \mathrm{~mL})$ at $0{ }^{\circ} \mathrm{C}$ were added ethylchloroformate $(868 \mathrm{mg}, 8.0 \mathrm{mmol})$ dropwise and the mixture was stirred for $30 \mathrm{~min}$. The solid was filtered off and the filtrate was added to the solution of tris(hydroxymethyl)aminomethane (892 $\mathrm{mg}, 7.3 \mathrm{mmol}$ ) and TEA (809 mg, 8.0 $\mathrm{mmol})$ in DMF $(10 \mathrm{~mL})$ for $10 \mathrm{~min}$. The reaction mixture was stirred for $30 \mathrm{~min}$ at $25{ }^{\circ} \mathrm{C}$. DMF was evaporated in vacuo. The residue was extracted with ethyl acetate $(50 \mathrm{~mL})$, washed with water. The solvent was dried over $\mathrm{MgSO}_{4}$ and evaporated to dryness. The crude product was purified by silica gel column chromatography to give desired product $4 \mathbf{a}$ (1.4 g, 85\%) IR $\max (\mathrm{KBr}) 3362,1620 \mathrm{~cm}^{-1}$; ${ }^{1} \mathrm{H}$ NMR $\left(\mathrm{DMSOd}_{6}, \delta\right) 7.80(\mathrm{~d}, 2 \mathrm{H}, J=1.2 \mathrm{~Hz}), 7.48(\mathrm{~m}, 3 \mathrm{H}), 7.25$ (s, 
1H), 4.80 (bs, 3H), 3.70 (s, 6H). MS-FAB (m/e) $226\left(\mathrm{M}^{+}+1\right)$. Anal. Calcd for $\mathrm{C}_{11} \mathrm{H}_{15} \mathrm{NO}_{4}$ : C, 58.66; H, 6.71; N, 6.22. Found: C, 58.60; H, 6.67; N, 6.13.

\section{References}

1. (a) Eastoe, J.; Rogueda, P. Langmuir 1996, 12, 2701. (b) Rodriguez, C.; Acharya, D. P.; Hattori, K.; Sakai, T.; Kunieda, H. Langmuir 2003, 19, 8692.

2. (a) Maag, H. J. Am. Oil Chem. Soc. 1984, 61, 259. (b) Hossain, M. K.; Acharya, D. P.; Sakai, T.; Kunieda, H. J. Colloid Interface Sci. 2004, 277, 235. (c) Rodriguez, C.; Sakai, T.; Fujiyama, R.; Kunieda, H. J. Colloid Interface Sci. 2004, 270, 483. (d) Rho, H. S.; Kim, D. H.; Kim, K. J.; You, J. W.; Kang, H. H.; Lee, O. S.; Park, J. H.; An, S. S.; Son, E. D. USP 6,521,662.
3. (a) Rho, J.-R.; Kim, Y. H. Bull. Korean Chem. Soc. 2005, 26 , 1457. (b) Radin, N. S. Bioorg. Med. Chem. 2003, 11, 2123

4. (a) Fernandez-Perez, M.; Otero, C. Enzym. Microb. Technol. 2001, 28, 527. (b) Furutani, T.; Furui, M.; Ooshima, H.; Kato, J. Enzym. Microb. Technol. 1996, 19, 578. (c) Maugard, T.; Remaud-Simeon, M.; Petre, D.; Monsan, P. Tetrahedron 1997, 53, 5185.

5. Polidori, A.; Pucci, B.; Zarif, L.; Lacombe, J.-M.; Riess, J. G.; Pavia, A. A. Chem. Phys. Lipids 1995, 77, 225.

6. Kim, D. H.; Rho, H. S.; You, J. W.; Lee, J. C. Tetrahedron Lett. 2002, 43, 277

7. Baily, P. D.; Collier, I. D.; Morgan, K. M. In Comprehensive Organic Functional Group Transformations; Katrizky, A. R.; Meth-Cohn, O.; Rees, C. W., Eds.; Pergamon: Oxford, 1995; Vol. $5, \mathrm{p} 264$. 